\title{
СТРАТЕГИИ ВОСПРИЯТИЯ ТЕКСТА ПРИ ОЦЕНКЕ НАПРЯЖЁННОСТИ СЮЖЕТА И ХАРАКТЕРА ДВИЖЕНИЯ СЮЖЕТНОГО ВРЕМЕНИ В ДЕТЕКТИВНЫХ ПРОИЗВЕДЕНИЯХ А. КРИСТИ: ПСИХОЛИНГВИСТИЧЕСКИЙ АСПЕКТ
}

\begin{abstract}
THE STRATEGIES OF TEXT PERCEPTION USED BY THE TEXT RECIPIENTS WHILE ASSESSING THE PLOT TENSION AND

THE PECULIARITIES OF THE PLOT TIME MOTION IN DETECTIVE NOVELS BY
\end{abstract} A. CHRISTIE: PSYCHOLINGUISTIC ASPECT

N. Peshkova Yu. Andrianova

Summary: The given article describes a psycholinguistic experiment aimed to study the strategies of text perception, used by the recipients while assessing the level of such text characteristics as plot tension and the peculiarities of plot time motion. The theoretical basis of the experiment as well as the methods of its' procedure and interpretation are also given here. As a result of the experiment quantitative and dynamic values of the intensity of emotional and intellectual reactions of the text recipients have been got. The analysis of these values made it possible to reveal the mental strategies activated in the reader's consciousness when percepting a fiction text. As a result of the experiment it was also possible to see the reactions of plot time motion assessment and reactions revealing the correlations between the use of tense forms in the text and plot time perception.

Keywords: plot tension, plot time motion, plot structure, reference points, microcontext, introspection method, the quantitative analysis.

\section{Введение}

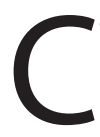

тратегии мышления, активизируемые в сознании реципиентов текста при его восприятии, составляют предмет особого интереса учёных-психолингвистов и, поскольку они способны дать информацию о функционировании языкового сознания личности в процессе восприятия письменного текста. Знания в этой области могут оказаться полезными при изучении воздействия функциональных стилей на реципиентов текста, а также для создания рекомендаций авторам текста, направленных на оптимальное сообщение информации и распространение идей в обществе.

Использование психолингвистической парадигмы в изучении восприятия реципиентом текста его содер-
Пешкова Наталья Петровна

д.филол.н., профессор, Башкирский государственный

университет, г. Уфа

Андрианова Юлия Геннадиевна

стариий преподаватель, Уфимский Государственный Нестяной Технический университет; соискатель, Башкирский государственный университет, г. Уфа yuliya-andrianov@mail.ru

Аннотация: В статье описывается психолингвистический эксперимент, направленный на изучение стратегий восприятия текста, активируемых в сознании реципиента при оценке такой текстовой характеристики, как напряжённость текста, описаны теоретические основы эксперимента и методики, относящиеся к процедуре его проведения и интерпретации результатов. В результате проведения эксперимента были получены квантитативные показатели интенсивности эмоциональной и интеллектуальной реакции испытуемых на воспринимаемый текст, выявляющие их оценку напряжённости и характера движения сюжетного времени в связи с употреблением автором конкретных грамматических средств (грамматических форм времени).

Ключевые слова: напряжённость сюжета, сюжетная структура, референциальные точки, метод интроспекции, количественный метод анализа. жания представляется нам наиболее подходящим инструментом для раскрытий стратегий мышления при понимании смысла художественного произведения. Смысл в психолингвистической парадигме понимается как «проекция сознания на текст», строящаяся за счёт привлечения к восприятию пресуппозиционных знаний и перекомпоновки в сознании импликативной текстовой информации [16]. В данной работе предлагается изучение стратегий восприятия текста художественного произведения, а именно детективного текста, при оценке уровня напряжённости его сюжета и характера движения времени в нём. Следует отметить, что категория напряжённости сюжета признаётся неотъемлемой характеристикой любого текста многими авторами лингвистических исследований [1;21]. Для нашего исследования наиболее подходит определение, данное 
А.В. Лещенко: «Нарративная напряженность представляет собой сложный многоуровневый конструкт, характеризуемый совокупностью универсальной, жанровой и внутритекстовой напряженности и реализуемый как на уровне его когнитивной модели (имеющей универсальные и жанрообразующие признаки), так и на уровне семиотического пространства текста, содержащего эксплицированные показатели нарративной напряженности - интеллективные и эмотивные триггеры» [14].

Основной задачей нашего исследования является рассмотрение развития сюжетного времени в произведении с точки зрения восприятия его читателем, что приводит нас к выбору метода, основанного на изучении реакций на воспринимаемый текст. Для целей нашего исследования мы выбрали метод психолингвистического эксперимента, базовые принципы которого были описаны в работах А.И Новикова[16] и Н.И. Жинкина [13]. Аудиторией для эксперимента нами были выбраны студенты 1 и 2-го курса уфимского государственного нефтяного технического университета, имеющие уровень базовой языковой подготовки от Upper Intermediate до Advanced, обучающиеся в группах с углублённым изучением иностранного языка. В качестве материала для изучения нами было избрано произведение А. Кристи.

В своём выборе направления исследования мы исходили также из предпосылок связанных с:

1. особой значимостью сюжетного времени для развития событий в рамках литературного произведения [6, с. 234; 7 ,с.11]);

2. взаимосвязью между принципами развития сюжетного времени в рамках текстов произведения и жанром произведения [18;19];

3. особо высоким уровнем напряжённости сюжетов именно произведений детективного жанра $[1$, с. $130 ; 5$, с. 53-55; 18,с.17].

Проведённое исследование состояло из следующих этапов:

1. предварительной работы, включающей в себя анализ структуры текстов детективных произведений в сочетании с рассмотрением особенностей движения сюжетного времени на каждом из участков произведения и выявлением причин этих особенностей;

2. подготовки и проведения психолингвистического эксперимента со студентами;

3. анализа и интерпретации результатов первой части эксперимента.

1 Структура сюжета Аетективного произведения и микроконтекст Авижения сюжетного времени в нём

Как уже было сказано выше, на первом этапе рабо- ты мы обратили внимание на принципы организации структуры детективных произведений, уровни напряжённости сюжета на каждом из его этапов и причины различий в ходе движения сюжетного времени на каждом из участков текста. В первую очередь было необходимо рассмотреть общую структуру организации текста произведения детективного жанра с целью выявить его значимые компоненты и те логические взаимосвязи между ними, которые были даны в литературоведческих исследованиях, для последующего их анализа с точки зрения восприятия текста в рамках психолингвистического исследования.

Практически все существующие сейчас классификации сюжетных элементов детективного произведения отталкиваются от классической структурной модели текста, содержащей такие элементы, как завязка сюжета, его кульминация и развязка. Вместе с тем, структура сюжета произведения всегда находится в тесной зависимости от его жанровой принадлежности, и вышеупомянутые элементы общей структуры художественного произведения могут рассматриваться, как блоковые компоненты, заключающие в себе менее масштабные, но от этого не менее значимые элементы сюжетной структуры. Если рассматривать произведения детективной литературы, то в их сюжетной структуре различные исследователи предлагают выделять значительно большее количество компонентов. Так, Янина Маркулан предлагает классификацию, состоящую из 8 элементов [15, с.6-50], а структура сюжета детективного произведения, предлагаемая в диссертации Р.Р. Теплых, состоит из 6 элементов [19, с. 28-29]. Создавая свою классификацию сюжетных элементов детективного произведения, в которой были выделены 9 элементов, мы учитывали материалы обоих предыдущих исследований. Также была принята во внимание позиция Н.Н. Вольского о значительной роли для развития сюжета детективного произведения эпизодов некриминального содержания, относящихся к повседневной жизни людей $[11$, с.9]. Таким образом, в созданную нами классификацию вошли, в отличие от вышеупомянутых классификаций, не только элементы, связанные с раскрытием криминальной ветви сюжета, но и те, что затрагивают некриминальные компоненты истории.

Каждому из элементов сюжетной структуры произведения присуща особая форма текстовой организации. Принципы текстовой организации в их взаимосвязи с содержанием сообщаемой в тексте информации были рассмотрены с позиций психолингвистической парадигмы в монографии Н.П. Пешковой [18, с.157]. Проанализировав 32 детективных произведения А.Кристи общим объёмом 8362 стр., мы получили следующую корреляцию между стадиями развития сюжета и доминирующими формами текстовой организации: 
Таблица 1.

Соотношение стадии развития сюжета детективного текста и типа используемой в нём текстовой организации

\begin{tabular}{|c|c|}
\hline Стадия развития & Тип текстовой организации \\
\hline Экспозиция & Описание, повествование \\
\hline Обнаружение преступления & Описание, повествование \\
\hline $\begin{array}{c}\text { Стадии расследования } \\
\text { преступления }\end{array}$ & $\begin{array}{c}\text { Описание, монолог-рассуждение, } \\
\text { диалог, полилог }\end{array}$ \\
\hline Эпилог & $\begin{array}{c}\text { Описание, повествование, моно- } \\
\text { лог-рассуждение, диалог, полилог }\end{array}$ \\
\hline
\end{tabular}

В рамках каждого из выделенных сюжетных элементов с присущими им типами текстов все используемые автором произведения лексические и грамматические средства создают тот специфический микроконтекст, в котором происходит движение сюжетного времени. О микроконтекстах и характерных для них доминантах движения времени мы упоминали в одной из наших предыдущих статей [2, с.460]. Под доминантой движения сюжетного времени в художественном произведении следует понимать вектор развёртывания событий в рамках произведения в целом либо в рамках отдельных его фрагментов.

В любом литературном произведении, согласно утверждению 3.Я. Тураевой, существуют референциальные точки, запускающие движение времени как на всём протяжении произведения, так и на каждом из его этапов. В предложенной ею терминологии они обозначались как «векторные нули»: «Для художественнго времени релевантно не столько условное значение «теперь», «сейчас», сколько упорядоченность, соотнесённость действий - «раньше, чем», «позже,чем». Это вполне совмещается с понятием векторного нуля, иначе точки приложения вектора» [20, с.47].

Таким образом, структуру движения сюжетного времени в детективном произведении можно описать как действие микроконтекста в элементах структуры произведения с учётом референциальных точек, запускающих определённое направление движения времени в нём.

2 Микроконтекст и направление $\Delta$ вижения
пжетного времени в петективном литературном
произведении

Как уже было сказано выше, каждый из элементов сюжетной структуры художественного произведения характеризуется определённым микроконтекстом, в рамках которого задаётся определённый принцип движения сюжетного времени, который впоследствии должен сформироваться в определённую картину движения времени в сознании реципиента текста.
Рассматривая стадию введения читателей в ситуацию повествования, или экспозиции, мы можем отметить уверенное и поступательное движение сюжетного времени вперёд.

Стадия совершения преступления запускает новую матрицу движения времени в произведении - сочетание ретроспекции и проспекции. Соотношение направлений вектора сюжетного времени коррелирует с объёмом информации о реконструируемых работниками следствия событиях, относящихся к преступлению. Чем боьше объём полученной и верифицированной следователями информации, тем меньше объём ретроспекции. В тот момент, когда соотношение информации из прошлого с известными в настоящем фактами достигает 100:100, наступает момент изобличения преступника, который также меняет вектор движения сюжетного времени в поизведнии.

В завершающей части детективных произведений время движется вперёд.

Каждому из элементов сюжетной структуры произведения присущ определённый уровень напряжённости сюжета. Так, на стадии экспозиции уровень напряжённости может считаться достаточно низким, поскольку никаких событий, кардинально меняющих общий уклад жизни и мироощущение героев, не происходит. Стадия расследования может априорно считаться имеющей более высокий уровень напряжённости, так как она связана с самым важным событием в произведении - преступлением. После стадии изобличения преступника, которая может считаться одной из наиболее значимых и напряжённых в сюжете произведения, наступает завершение произведения или эпилог. На данной стадии трудно ожидать резких поворотов сюжета, поэтому здесь трудно представить себе достаточно высокий уровень напряжённости. Все события, как правило, ведут к счастливому разрешению судьбы героев и конечной победе добра над злом [21].

На основании всего сказанного выше можно сделать вывод о том, что движение сюжетного времени в детективном произведении обусловливается следующими факторами:

1. общей структурой сюжета произведения;

2. действием референциальных точек на общем векторе движения сюжетного времени, изменяющих его направление;

3. уровнем напряжённости развития сюжета.

3 Субъективный и объективный факторы в определении референшиальных точек, влияюших на изменение хо $\Delta а$ виякения сюжетного времени

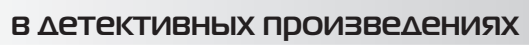

Определение референциальных точек движения сю- 
жетного времени в рамках литературного произведения тесно связано с его анализом. Анализ текста литературного произведения связан не только с обязательным адекватным использованием элементов научной парадигмы исследования, но и с действием факторов субъективного восприятия содержания текста исследователем, что часто ставит под вопрос валидность работ в данной сфере. Таким образом, литературный анализ следует считать деятельностью, в которой должен проявляться баланс между объективным и субъективным факторами [12].

С точки зрения А. Б. Есина такой баланс может быть достигнут в том случае, если объективации подвергается не только текст художественного произведения, но и те эмоциональные реакции, которые он вызывает в воспринимающем его читателе [12]. Следует отметить, что данный подход коррелирует с позицией Н.И. Жинкина и А.И. Новикова об активной роли реципиента текста художественного текста[13;16], а также с мнением М.М. Бахтина о диалогичности, как неотъемлемой черте текста художественного произведения [6]. В качестве способа, примиряющего субъективный и объективный элемент в литературном исследовании, А.Б. Есин предлагает использовать метод самоанализа эмоционального состояния читателя [12]. Полезность использования данного метода в исследованиях указывает также Н.П. Пешкова [17].

В своей работе мы выдвигаем гипотезу о том, что 6 основе определения референциальных точек 6 системе временных координат художественного произведения на уровне восприятия текста лежит принцип оценки уровня напряжённости сюжета в каждом из элементов текста, коррелирующий с уровнем интенсивности эмоциональной реакции реципиента текста на его содержание. Она базируется на положении о потенциально высоком уровне эмоционального напряжения, создаваемого в поворотных элементах сюжета, что должно найти отражение в сознании реципиента текста [8].

Возникла необходимость в методе, позволяющем максимально точно и с минимальным уровнем субъективности произвести оценку интенсивности эмоциональной реакции реципиента текста. Наиболее доступным средством для обеспечения строгой оценки является применение метода шкалирования. Достаточно высокое мнение учёных о степени валидности данных, получаемых в результате применения этого метода, также склоняют нас в его пользу[10].

В ходе эксперимента предполагалось получить определённый набор числовых показателей, характеризующих изменение интесивности эмоциональной реакции читателей, вызванных изменением напряжённости сюжета. Мы предположили, что точки, отражающие мак- симальный уровень эмоциональной реакции реципиентов текста, отражают не только высокий уровень напряжённости в конкретном участке произведения, но и являются референциальными точками, запускающими новую матрицу движения сюжетного времени в произвведении.

4 Методика анализа напряжённости сюжета

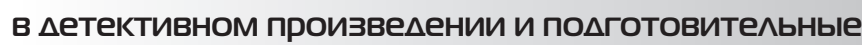
этапы работы нах экспериментом

Для осуществления идеи об объективации эмоциональных реакций на содержание текста через использование метода числовых измерений, мы решили организовать первую стадию нашего психолингвистического эксперимента в форме опроса.

В основе данного выбора лежало предположения о том, что принимающие участие в эксперименте студенты способны к рефлексии по поводу своего эмоционального состояния, вызванного содержанием прочитанного текста, а также способны проинтерпретировать его таким образом, чтобы обеспечить его презентацию в виде числовых показателей уровня напряжённости сюжета.

В качестве показателей уровня напряжённости мы выдвинули следующие характеристики:

1. значение текстового элемента для изменения общего хода повествования в текте;

2. уровень эмоционального воздействия на читателя.

Целью проводимого нами опроса являлось изучение стратегий восприятия характера движения сюжетного времени в детективном произведении, а также рассмотрение корреляций между употребляемыми грамматическими формами глагола и восприятием характера движения сюжетного времени в тексте.

Методы измерения и анализа материалов эксперимента. Мы предположили, что метод использования шкалы в оценке степени активности эмоциональной реакции реципиентов может обеспечить высокую точность анализа реакций участников эксперимента на воспринимаемый текст. Отвергнув методику семантического дифференциала Ч. Осгуда [3] и методику интегрального исчисления значения лексических единиц в тексте предлагаемую Н.Н. Аюшевой и Н.Н. Кушуевой [4;3], мы пришли к выводу о том, что в своей работе с результатами эксперимента мы будем пользоваться следующими методами:

1. процентно-пропорциональным методом, позволяющим определить процентное соотношение конкретных реакций реципиентов к общему массиву предоставленных реакций;

2. методом сравнения с целью выявления коррелирующих реакций для определения средних 
числовых показателей и выявления общих стратегических линий восприятия и понимания текста произведения на основании полученных корреляций.

Отбор аудитории для эксперимента. Успешность проведения любого опроса базируется на построении валидной репрезентативной выборки, с достаточной степенью надёжности отражающей общий объём генеральной совокупности [9]. Целевой аудиторией нашего эксперимента являются студенты 1-го и 2-го курса уфимского государственного нефтяного технического университета. Используя параметрический подход к определению генеральной совокупности участников эксперимента, в котором в качестве базового критерия был задан параметр владения иностранным языком на уровне Upper Intermediate или Advanced, мы определили генеральную совокупность из 134 студентов, обучающихся в группах с углублённым изучением иностранного языка. Задав имеющемуся на сайте социологических расчётов калькулятору параметры точности в 95\% и погрешности в 5\%, мы получили объём репрезентативной выборки в 100 человек [22].

Подготовка инструкции для эксперимента. Предлагаемая студентам инструкция включала два вида заданий: одно направленное на количественную оценку эмоциональной реакции на презентуемый текст и второе - на изучение качественной оценки эмоций, вызванных прочитываемым текстом. Последнее должно было быть представлено текстами, обосновывающими выбор студентами конкретных текстовых элементов в качестве референциальных точек.

Задания на эксперимент для студентов звучали так:

1. Прочтите данное произведение, выделите в нём значимые участки текста с точки зрения изменения сюжета и эмоционального воздействия на Вас. Определите уровень напряжённости сюжета на каждом из выделенных Вами участков текста по шкале от 0\% до100\% (где 0\% соответствует полному отсутствию текста).

2. Аргументируйте избранный Вами уровень напряжённости сюжета для каждого из участков текста, представив краткое изложение Ваших мыслей по поводу их содержания в виде мини-текста.

3. Если Вы отметили связь между выделенными значимыми элементами текста и характером движения сюжетного времени в нём, отметьте, пожалуйста, это в составленных Вами текстах.

В качестве материала для исследования студентам был предложен роман А. Кристи: “The Pale Horse"[23], так как он малоизвестен и не был экранизирован, а, следовательно, мог обеспечить нам большую чистоту эксперимента, за счёт отсутствия у студентов опоры на пред- варительно полученные знания и впечатления.

\section{1 Ход эксперимента}

Перед началом непосредственной части эксперимента была избрана его стратегия. В целях минимизации влияния экспериментаторов на результаты эксперимента, его решено было проводить в дистанционном режиме, где студенты предоставляли бы свои ответы по электронной почте. Для снятия возможных затруднений при восприятии некоторых фрагментов текста было решено использовать факультативные занятия по иностранному языку, на которых проводилось разъяснение подобных моментов и ознакомление с некоторыми принципами анализа текста художественного произведения. Следует отметить, что на этих занятиях не обсуждались сами реакции студентов, чтобы никак не повлиять на результаты эксперимента.

В начале эксперимента студенты были проинформированы о его целях и задачах, получили устные инструкции о том, как следует изучать предлагаемый текст, и листочки-памятки с указанием вопросов, на которые предстоит ответить.

Студентам был дан месячный срок на изучение романа.

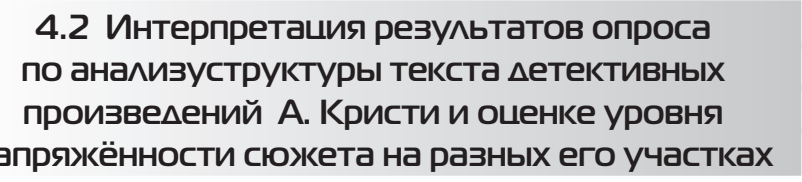

В процессе анализа материалов выяснился троякий подход студентов к анализу данного произведения: поверхностный, углублённый и детальный. При поверхностном анализе студенты выделяли введение, криминальные моменты, следствие по делу и момент раскрытия преступления. При углублённом подходе студенты структурировали криминальную составляющую сюжета, оценивая значимость каждого из криминальных эпизодов и характеризуя влияние следственных действий на смысловую структуру сюжета произведения. При детальном подходе в поле зрения студентов попали события, относящиеся как к криминальной, так и к некриминальной ветвям развития сюжета. Следует отметить, что все респонденты произвели количественную оценку интенсивности своих эмоциональных реакций на воспринимаемый текст, снабдив их графиками изменения интенсивности реакций. Вместе с тем, только студенты, проделавшие углублённый и детальный анализ текста, представили тексты, аргументирующие выбор значимых для развития сюжета референциальных точек. В общем массиве ответов, реакции, отражающие различный подход к анализу текста распределились следующим образом: 
Таблица 2.

Объём реакций, отражающих поверхностный, углублённый и детальный уровни анализа текста романа

\begin{tabular}{|l|c|c|}
\hline \multicolumn{1}{|c|}{ Тип анализа } & Количество реакций & $\begin{array}{c}\text { \% соотношение } \\
\text { кобщему массиву } \\
\text { реакций }\end{array}$ \\
\hline поверхностный & 30 & $30 \%$ \\
\hline углублённый & 50 & $50 \%$ \\
\hline детальный & 20 & $20 \%$ \\
\hline
\end{tabular}

При поверхностном анализе текста количество выделенных респондентами референциальных точек колебалось от 4 до 9. Наибольшее представительство получила структура из 5 точек (14 ответов, что составляет 47\%), наименьшее - 4-х компонентная структура (3 ответа, что составляет 10\%). В рамках углублённого анализа были выделены структуры, состоящие из 5, 6, 8 и 9 референциальных точек. В группе доминировала 9-ти компонентная структура, представленная 35 ответами, что составило 70\% от общего количества ответов. Далее следуют 5-и и 8-и компонентные структуры (16\% и 12\% ответов соответственно). 6-компонентная структура представлена единичным ответом, что составило 2\% от общего числа реакций. В рамках детального анализа определены структуры из 8, 9,12,13,17,18,21,22 и 35 референциальных точек. Здесь самой многочисленной оказалась группа из ответов, в которых было выделено 9 значимых компонентов (35\% от общего количества ответов), а наименее представленной оказалась 35-компонентная структура, указанная в единичном ответе, что составляет по $5 \%$ от общего объёма реакций.

Рассматривая поверхностный анализ текста, в котором были выделены всего 4 референциальные точки, мы увидели, что респонденты отметили для себя, как значимые, только такие моменты произведения, как введение, момент совершения преступления и эпилог, т.е. в своих оценках они опирались на пресуппозиционные знания,

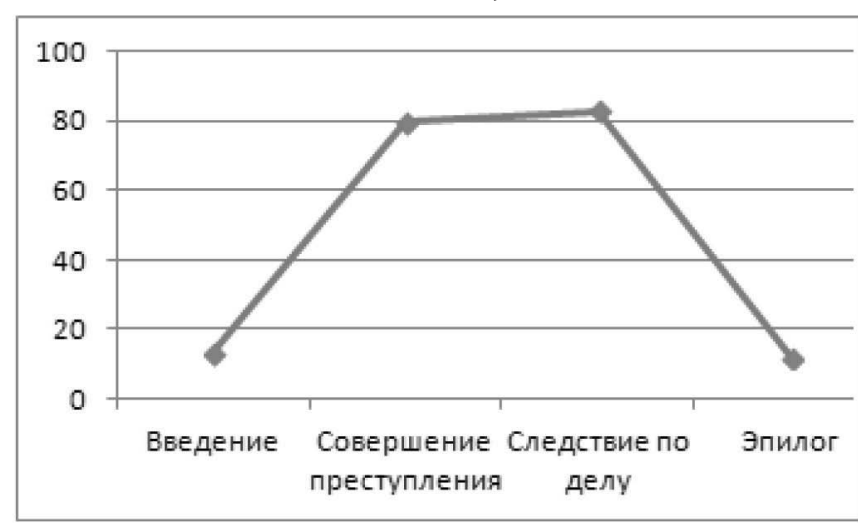

Рис.1. Изменение интенсивности эмоциональных реакций респондентов, проделавших поверхностный анализ текста, выделивших 4 значимых компонента в нём полученные из школьного курса по анализу художественных текстов, так как данная структура очень близка классической, трёхкомпонентной. Кроме того, здесь проявилась селективность в отборе воспринимаемого материала в пользу криминальной линии произведения. На основании корреляции между ответами в данной подгруппе по количеству выделенных элементов, мы смогли построить следующий график динамики изменения интенсивности реакций на воспринимаемый текст, используя средние значения уровня эмоциональной реакции в каждой из выделенных референциальных точек:

В группе 5-компонентных структур сюжета произведения, мы выяснили, что здесь при сохранении общей тенденции к селективности анализируемого материала в пользу криминальной линии произведения, студенты проявили большее внимание к процессу следствия, дифференцировав в нём моменты, относящиеся собственно к работе по анализу фактов и момент изобличения преступника. Здесь, как и в предыдущем случае, происходит проявление тенденции к компрессии воспринимаемого материала. В данном случае на основании средних значений мы получили следующий график:

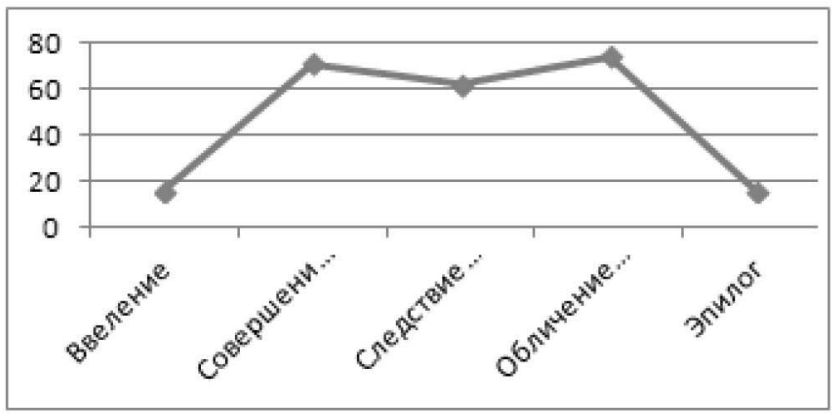

Рис.2. Изменение интенсивности эмоциональных реакций респондентов, проделавших поверхностный анализ текста, выделивших 5 значимых компонентов в нём

В структуре из 9 компонентов просматривается не только общая для данной группы селективность материала в пользу криминальной линии, но и большее внимание респондентов к содержанию текста. Так, ими были выделены и отдельно оценены разнообразные криминальные эпизоды, а также отдельно восприняты и оценены элементы следствия. Высокие оценки интенсивности эмоциональной реакции на эпизоды убийства (в диапазоне 60-64\%) можно объяснить проявлением эмпатии реципиентов текста по отношению к жертвам, а также оценкой вклада каждого из данных событий в общую смысловую ткань произведения. Разделение процесса следственной деятельности на работу на начальном этапе и на последующее объединённое расследование всех криминальных случаев в романе показывает привлечение реципиентами текста пресуппозиционных правовых знаний. 
Таким образом, при рассмотрении поверхностного анализа текста детективного произведения мы можем выделить следующие применяемые ими стратегии: использование пресуппозиции, эмоциональной и аксиологической оценки содержания текста, сравнительный анализ событий с точки зрения их смысловой значимости для сюжета произведения.

На уровне углублённого анализа в некоторых случаях наблюдается применение тех же стратегий, что и при поверхностном анализе. В частности, отмечается селективность материла в пользу криминальной линии при построении структуры из 5 компонентов - в данном случае график совпал по конфигурации с построенным при поверхностном анализе текста. В 8 компонентной структуре просматривается более детальный подход к изучению криминальной линии романа. Следует отметить, что разнообразие выбранных студентами значимых компонентов текста не позволили нам построить график динамики эмоциональных реакций по усреднённым значениям активности реагирования.

При детальном анализе текста романа имеет место значительное разнообразие выделяемых респондентами значимых компонентов текста. Была отмечена корреляция между количеством выделяемых значимых компонентов текста и уровнем сложности и разнообразия применяемых реципиентами текста стратегий. В частности, наряду с аксиологической оценкой и использованием пресуппозиции, присутствует аспект построения ассоциативной связи между событиями.

Итак, мы видим, что при восприятии содержания текста произведения респонденты использовали такие стратегии как: пресуппозиция, аксиологическая и эмоциональная оценка событий, селективность и компрессия при восприятии материала. Также наряду с ними проявляются тенденция к дискретности, повышенной рациональности и ассоциативности в восприятии текстовых элементов.

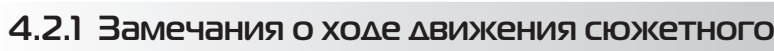 времени в романе}

В своих ответах респонденты, проделавшие углублённый и детальный анализ текста, отметили связь между характером развития сюжета и движением сюжетного времени в нём. Респондент А.Ш. написала: «Здесь есть два типа движения времени. У полиции оно хоть и, как в жизни, идёт вперёд, в том, что касается дела, оно никуда не движется. Всё за них делает Осборн. Он возвращает их в тот день, когда погиб Отец Гормон, своими письмами и свидетельствами. Марк Истербрук постоянно движется вперёд. Только в середине романа Марк объединяет усилия с полицией, и они вместе начинают движение из настоящего в прошлое, в события со всеми людьми из списка, к завершению романа. Тут у них как бы совместное какое-то время появляется. А потом, в конце, время постоянно идёт вперёд».

Некоторые из респондентов указывали на связь между применением автором романа конкретных грамматических форм времени и восприятием интенсивности и скорости движения времени. В частности, респондент Т.Д. отметил связь между употреблением автором романа времени Present Indefinite и медленной визуализацией событий в некоторых отрывках текста: «В сцене драки в кафе, где много Present Indefinite, возникает ошущение, что смотришь фильм с раскадровкой. Мне показалось, что это из-за того, что это время всегда описывает единичные действия. Bom: "Suddenly they were screaming at each other. One girl slapped the other's face, the second dragged the first from her chair. They fought each other like fish-wives, screaming abuse hysterically."[22, с.22] Факты визуализации и изменения интенсивности движения времени отметили $30 \%$ принявших участие в опросе респондентов. Большинство из них также увязывали свои ощущения с употреблением автором конкретных видовременных форм глагола.

\section{Выводы}

В результате проделанного нами исследования мы получили следующие результаты:

1. При восприятии текста большинство респондентов применяли стратегии селективности и компрессии изучаемого текстового материала, аксиологической оценки событий и сравнительный подход в оценке их значимости для смысловой структуры текста. Наряду с ними на характер интенсивности эмоциональной реакции влиял фактор наличия или отсутствия у респондентов пресуппозиционных правовых знаний.

2. При рассмотрении структуры сюжета произведения в языковом сознании воспринимающей его личности её состав может значительно отличаться от классического, так как привлекаемые для восприятия текста эмоционально-интеллектуальные стратегии уникальны для каждого реципиента. Представленные нашими респондентами ответы показали, что в ней может находиться до 35 значимых компонентов.

3. Сознание языковой личности воспринимает взаимосвязь между содержанием текстовых элементов произведения и характером движения сюжетного времени в них. Также оно отмечает разнонаправленный характер движения времени в произведении в целом и движение «времени героя» (см. реакцию респондента А.Ш. выше) и фиксирует связь между образностью произведения, вызывающей эффекты визуализации, для которых характерна специфическая скорость движения 
сюжетного времени, и употреблением конкретных грамматических форм времени.

\section{Зак^ючение}

Проведённое нами исследование показывает, что для понимания и изучения движения художественного времени в произведении необходимо сочетать изучение структуры произведения с изучением эмоциональных реакций реципиентов на предъявляемый текст, т.к. использование данного метода позволяет создавать относительно объективную картину восприятия развития сюжета во времени, оценивать уровень его сложности и напряжённости.

\section{ЛИТЕРАТУРА}

1. Адмони В.Г. Система форм речевого высказывания.- СПб., 1994.- С. 130.

2. Андрианова Ю.Г. Движение времени в произведениях англоязычной детективной прозы// Вестник Башкирского Государственного Университета - Уфа: РИЦ БашГУ,2018 -С. 457-461

3. Андрианова Ю.Г. Выбор методики психолингвистического анализа смысловой и сюжетной структуры произведения художественной литературы// Межкультурная↔интракультурная коммуникация: теория и практика обучения и перевода -Уфа: РИЦ БашГУ,2018. - С.30-35

4. Аюшева Н.Н., Кушуева Т.Н. Способ расчета весовых коэффициентов вершин семантической сети научного текста // Фундаментальные исследования. 2012. - № 6-3. - С. 626-630; [Электронный ресурc] URL: http://fundamental-research.ru/ru/article/view?id=30087 (дата 0бращения: 04.11.2018)

5. Бабенко Л.Г., Васильев И.Е., Казарин Ю.В. Лингвистический анализ художественного текста. - Екатеринбург, 2000. - 533 с.

6. Бахтин М.М. Автор и герой в эстетической деятельности. Проблема отношения автора к герою// Эстетика словесного творчества - М.: Искусство, 1979-325с.

7. Бахтин М.М. Формы времени и хронотопа в романе. Очерки по исторической поэтике//Бахтин М.М. Вопросы литературы и эстетики. - М.: Худож. лит., 1975. - С.234-407.

8. С.П. Белокурова Словарь литературоведческих терминов [Tекст] URL:http://gramma.ru/LIT/?id=3.0 (дата обращения:25.04.2020)

9. Березин И.С. Практические способы построения выборки в измерениях и опросах - [Tекст] - URL: http://www.elitarium.ru/issledovanie-vyborkareprezentativnost-dostovernost-doveritelnyj-interval-formuly/ - Дата обращения 21.10.2018

10. Волков Ю.Г., Добреньков В.И., Нечипуренко В.Н., Попов А.В.. Социология: Учебник / Под ред. проф. Ю.Г. Волкова. — Изд. 2-е, испр. и доп. — М.: Гардарики,2003. - 512 с

11. Вольский Н.Н. Легкое чтение. Работы по теории и истории детективного жанра. Новосибирск, 2006 - с. 5-126

12. Есин А.Б. Принципы и приемы анализа литературного произведения. - М., 1998г.- 235с.

13. Жинкин Н.И. Речь как проводник информации - М., $1982-326 c$.

14. Лещенко А.В. Анализ интеллективных триггеров напряжённости (на материале криминальных рассказов А. Kристи) - [Tekст] - URL https://revolution. allbest.ru/languages/00840991_0.html\#text (дата обращения:25.04.2020)

15. Маркулан Я. Зарубежный кинодетектив. Опыт изучения одного из жанров буржуазной массовой культуры. - Л.: Искусство, 1975. - с. 6-50.

16. Новиков А.И. Текст и «контртекст»: две стороны процесса понимания//Вопросы психолингвистики - 2003 - №1 - С.64-76

17. Пешкова Н.П. Психолингвистика текста: курс лекций / Н.П. Пешкова - Уфа: РИЦ БашГУ, 2015. - 148с.

18. Пешкова Н.П. Типология текста: психолингвистический аспект (на материале научных, научно-популярных и технических текстов) - Уфа: РИЦ Баш$\Gamma \mathrm{Y}, 2015-269 \mathrm{c}$

19. Теплых Р.Р. Концептосфера английских и русских детективов и их языковое представление: Диссертация канд. филол. наук Уфа,2007-181с.

20. Тураева 3.Я. Категория времени. Время художественное и время грамматическое.- М., 1979 - 219с.

21. Шпар Е.В. Базовые категории текста: когнитивный аспект представления связности. - Уфа, Рио БашГУ, 2006. - 258 с.

22. http://www.blog.anketolog.ru - Режим открытого доступа - Дата обращения 23.06.2019

23. Cawelty J.G. Adventure, Mystery and Romance: Formula Stories as Art and Popular Culture. Chicago, 1976. -286p.

24. Agatha Christie The Pale Horse - СПб.: Kapo, 2009-320c.

(c) Пешкова Наталья Петровна, Андрианова Юлия Геннадиевна (yuliya-andrianov@mail.ru).

Журнал «Современная наука: актуальные проблемы теории и практики» 